\title{
An intelligent stochastic method based on fuzzy cloud theory for modeling uncertainty effects in the renewable micro-grids
}

Jafar Zare and Alireza Zare

Department of Electrical Engineering, Sarvestan Branch, Islamic Azad University, Sarvestan, Iran

The above article published in the Journal of Intelligent \& Fuzzy Systems volume 28, number 1 (2015), pages 421 to 431 has shown such strong similarities with the article by Sina Parhoudeh, A. Baziar, Alireza Mazareie and A. Kavousi-Fard entitled "A novel stochastic framework based on fuzzy cloud theory for modeling uncertainty in the micro-grids" and published in Electrical Power and Energy Systems 80 (2016) 73-80, http://dx.doi.org/10.1016/j.ijepes.2016.01.033 that it is considered a direct copy/duplicate publication.

Although the paper published in the Journal of Intelligent \& Fuzzy Systems (JIFS) was accepted and published online before the paper published in Electrical Power and Energy Systems (EPES) (published online in December 2014 for JIFS, February 2016 for EPES), both papers were submitted to the two journals around the same time but first to EPES (April 2014 for EPES, May 2014 for JIFS). All authors from both papers are with the Department of Electrical Engineering, Islamic Azad University, Iran. The Journal of Intelligent \& Fuzzy Systems has not been able to receive an adequate explanation from the authors Jafar Zare and Alireza Zare regarding the similarity between the two papers which were submitted by different authors from the same department to two different journals at around the same time and has decided to withdraw this duplicate publication from the scientific record. 